\title{
Half antiperovskites VII - DFT modelling of shandites that are isoelectronic to $\mathrm{Co}_{3} \mathrm{Sn}_{2} \mathrm{~S}_{2}$
}

\author{
Clara Marx, ${ }^{[\mathrm{a}]}$ Jan Endriss, ${ }^{[\mathrm{a}]}$ Maxi Klopfer, ${ }^{\left[{ }^{[a]}\right.}$ Werner Reichel ${ }_{1}^{[\mathrm{a}]}$ Christian Strakos, ${ }^{[\mathrm{a}]}$ and \\ Richard Weihrich*[a]
}

Dedicated to Prof. Dr. R. Dronskowski on the occasion of his birthday

Our discovery of half metal ferromagnetic (HFM) properties on shandite type $\mathrm{Co}_{3} \mathrm{Sn}_{2} \mathrm{~S}_{2}=\mathrm{Sn}_{2} \mathrm{Co}_{3} \mathrm{~S}_{2}$ about 20 years ago by DFT calculations opened the gate for fascinating discoveries like giant anomalous Hall effect and Weyl semimetal characteristics. Thereby, interest arose on electronic and magnetic structure effects upon substitution of $M=C o$ and $A=S n$ sites in and between Co Kagomé layers. Non isoelectronic substitution to $A=\ln$ or $M=\mathrm{Ni}$ causes a decay of magnetic properties to

\section{Introduction}

Shandite is the mineral $\mathrm{Pb}_{2} \mathrm{Ni}_{3} \mathrm{~S}_{2}$, discovered in 1949 by Paul Ramdohr on a sample of the mineral heazlewoodit, $\mathrm{Ni}_{3} \mathrm{~S}_{2} \cdot{ }^{[1]} \mathrm{He}$ could synthesize the compound and correctly proposed its trigonal symmetry. It was confirmed by Peacock et al. (space group: $R \overline{3} m$, lattice parameters $\mathrm{a}=5.565 \AA, \alpha=60.2^{\circ}, \mathrm{V}=$ $\left.122.59 \AA^{3}, Z=1\right){ }^{[2]}$ In subsequent decades isotypic compounds $A_{2} M_{3} X_{2}$ were prepared by chemical synthesis with main group $A=\mathrm{In}, \mathrm{Sn}, \mathrm{Tl}, \mathrm{Pb}$, transition group metals $M=\mathrm{Co}, \mathrm{Ni}, \mathrm{Rh}, \mathrm{Pd}$, non-metals $X=\mathrm{S}$, Se). ${ }^{[3-9]}$ In search for interesting properties ferromagnetism was proposed for shandite and $\mathrm{Pb}_{2} \mathrm{Ni}_{3} \mathrm{Se}_{2}{ }^{[3]}$ but in subsequent studies ${ }^{[4-5]}$ only Pauli paramagnetism was found for shandites. Hillers results were attributed to Ni impurities.

Fascinating magnetism was however found for the cobaltshandite $\mathrm{Sn}_{2} \mathrm{Co}_{3} \mathrm{~S}_{2}$. It was first prepared by Zabel and Range ${ }^{[6]}$ in Regensburg and re-investigated there starting in 1998 with new insights in crystal and electronic structures, and properties. ${ }^{[7-9]}$ Its structure was refined and $\mathrm{Sn}_{2} \mathrm{CO}_{3} \mathrm{~S}_{2}$ was discovered as $\mathrm{S}={ }^{1} / 2$ half metal ferromagnet (HFM) from DFT calculations. ${ }^{[7-9]}$ The kink observed in conductivity versus temperature curves by Natarajan et al. was attributed to a transition from a Pauli paramagnet to a band ferromagnet below $T_{C}=-97^{\circ} \mathrm{C}(176 \mathrm{~K})$.

[a] C. Marx, J. Endriss, M. Klopfer, W. Reichel, C. Strakos,

Prof. Dr. R. Weihrich

Institute for Materials Resource Management, University of Augsburg,

Am Technologiezentrum 8, D-86159 Augsburg, Germany

E-mail: richard.weihrich@uni-a.de

of () 2021 The Authors. Zeitschrift für anorganische und allgemeine Chemie published by Wiley-VCH GmbH. This is an open access article under the terms of the Creative Commons Attribution NonCommercial NoDerivs License, which permits use and distribution in any medium, provided the original work is properly cited, the use is non-commercial and no modifications or adaptations are made. semiconducting diamagnetic $\mathrm{InSnCO} \mathrm{S}_{2}$ or paramagnetic semi metal $\mathrm{Ni}_{3} \mathrm{Sn}_{2} \mathrm{~S}_{2}$. The present study addresses simultanious substitutions on both $A$ and $M$ sites to novel isoelectronic compounds of $\mathrm{CO}_{3} \mathrm{Sn}_{2} \mathrm{~S}_{2}$. Therefore, DFT calculations were performed on model structures $M M_{2}^{\prime} A A^{\prime} X_{2}(M=\mathrm{Fe}, \mathrm{Co}, \mathrm{Ni} ; A=\mathrm{In}$, $\mathrm{Sn}, \mathrm{Sb} ; X=\mathrm{S})$. By the given approach, target compositions are identified that are interesting for future investigations and discoveries.

A simple description of the crystal structure of shandites $A_{2} M_{3} X_{2}$ was developed from the "role" of the $A, M$, and $X$ atoms. ${ }^{[10-12]}$ In shandites, monoclinic and cubic parkerites $\mathrm{Bi}_{2} \mathrm{Ni}_{3} \mathrm{~S}_{2}$ and $\mathrm{Bi}_{2} \mathrm{Pd}_{3} \mathrm{~S}_{2}$ the main group metals $A$ form a simple primitive structure centered by $X$. The $M$ atoms are found in tetragonal bipyramieds $A_{4} X_{2}$ similar to antiperovskites $A M_{3} X$ like $\mathrm{MgNi}_{3} \mathrm{C}$. As in shandites and parkerites only half of $M$ sites are occuped, they were called "half antiperovskites" $A M_{3 / 2} X=$ $A_{2} M_{3} X_{2}$. Interestingly, a similar structure relation was described by Hoppe to oxostannates like $\mathrm{K}_{2} \mathrm{Sn}_{2} \mathrm{O}_{3}=\mathrm{KSnO}_{3 / 2}$. Similar to $\mathrm{Ti}-\mathrm{O}-\mathrm{Ti}$ bonds in perovskites the $\mathrm{M}$ atoms in antiperovskites are linearly coordinated by $S-M-S$ bonds in covalent $\left[M_{3} S_{2}\right]$ networks as mentioned by the description $A_{2}\left[M_{3} X_{2}\right]$.

A "chemical" understanding of electronic structure and HFM magnetism in $\mathrm{Sn}_{2} \mathrm{CO}_{3} \mathrm{~S}_{2}$ was derived from crystal structure and electron counting. ${ }^{[7-9]}$ HFM compounds are metals for one spin channel, but semi-conductors for the other. Respective Heusler alloys, $\mathrm{CrO}_{2}\left(\mathrm{Cr}^{4+}, 3 \mathrm{~d}^{2}\right)$, or $\mathrm{CoS}_{2}$ (low-spin $\mathrm{Co}^{2+}, \mathrm{d}^{7}, \mathrm{~S}=1 / 2$ ) are band ferromagnets, but their magnetism can be understood from ionic spin states. For $\mathrm{Sn}_{2} \mathrm{CO}_{3} \mathrm{~S}_{2}$ band structures predicted an $I_{A}$-type HFM with $S=1 / 2 \cdot{ }^{[7-9]}$ It is understood by $\mathrm{Co}(0)-3 d^{9}-$ states that interact within face sharing $\mathrm{Sn}_{4} \mathrm{~S}_{2}$ polyhedra. This causes the formation of a band gap between bands no. 23 and 24. In $\mathrm{Sn}_{2} \mathrm{CO}_{3} \mathrm{~S}_{2}$ (47 valence electrons, VE) the conduction band (CB) is occupied by only 1 electron that is responsible for its magnetism. Schnelle et al. and other groups confirmed the predicted HFM state experimentally. $\mathrm{Sn}_{2} \mathrm{CO}_{3} \mathrm{~S}_{2}$ turned out as highly anisotropic HFM that is magnetized perpendicular to $\mathrm{Co}$ kagomé nets. ${ }^{[13-16]}$

Substitution of $A=\mathrm{Sn}$ atoms by In cause a change in electron count and magnetism. $\operatorname{InSnCO}_{3} \mathrm{~S}_{2}$ (46 VE) has one electron less than $\mathrm{Sn}_{2} \mathrm{CO}_{3} \mathrm{~S}_{2}$. The fermi energy $E_{F}$ is shift into the gap. $\mathrm{InSnCO} \mathrm{S}_{3} \mathrm{~S}_{2}$ is a low gap semiconductor and thermoelectric material. ${ }^{[7-9]}$ Additionally, the electronic structure turned out 
sensitive to occupation of A-In, Sn between and in Co kagomé layer. Ordering of In and $\mathrm{Sn}$ modulates the band gap. ${ }^{[17-21]}$

Substitution on $M=$ Co sites $\mathrm{Sn}_{2} \mathrm{CO}_{3} \mathrm{~S}_{2}$ by $\mathrm{Ni}$ increases the number of electrons towards $\mathrm{Sn}_{2} \mathrm{Ni}_{3} \mathrm{~S}_{2}$ (50 VE). In solid solutions $\mathrm{Sn}_{2} \mathrm{Co}_{3-\mathrm{x}} \mathrm{Ni}_{\mathrm{x}} \mathrm{S}_{2}$ magnetism decays. ${ }^{[13]} \mathrm{It}$ is understood by filling the $d$-bands towards $\mathrm{Ni}(0)-3 d^{10[7,22]}$ compared to $\mathrm{Co}(0)-3 d^{9}{ }^{[9]}$ To the contrary, substitutions of $\mathrm{M}=\mathrm{Co}$ by $\mathrm{Fe}, \mathrm{Mn}, \mathrm{Cr}^{[23]}$ reduce the number of electrons. According to DFT calculations the respective compounds are predicted as HFM materials. However, they were not prepared to date except $\mathrm{Sn}_{2} \mathrm{FeCO}_{2} \mathrm{~S}_{2}$ that was found isoelectronic to $\operatorname{lnSnCo}_{3} \mathrm{~S}_{2}$ and semiconducting, too. ${ }^{[24]}$

Recently, the electronic structure for $\mathrm{Sn}_{2} \mathrm{CO}_{3} \mathrm{~S}_{2}$ was enriched by outstanding discoveries on $2 \mathrm{D}$ magnetism and topological properties. $^{[25-27]}$ Its giant anomalous Hall effect (GAHE) was intrinsically related to Weyl semimetal behavior. Now, focus turned on valence bands no. 24 and 25 that cross at two kpoints. Spin-orbit coupling opens gaps at the respective points at $E_{F}$ characterized as Weyl points. Accordingly, $\mathrm{Sn}_{2} \mathrm{CO}_{3} \mathrm{~S}_{2}$ was classified as magnetic Weyl-semimetal with large anomalous hall conductivity (AHC) and a huge anomalous hall angle (AHA). The electronic topology of the cobalt-shandite was estimated as a guide to the realization of strong AHE in magnetic and topological semimetals. Researchers started to exploit further properties of $\mathrm{Sn}_{2} \mathrm{CO}_{3} \mathrm{~S}_{2}=\mathrm{Co}_{3} \mathrm{Sn}_{2} \mathrm{~S}_{2}$ including zero field Nernst effect, thermoelectric and magnetocaloric properties, as well as critical and Skyrmion behavior (see e.g. ${ }^{[28-35]}$ ).

The discoveries shed light into the valence band region of $\mathrm{Sn}_{2} \mathrm{CO}_{3} \mathrm{~S}_{2}$ : all fascinating properties like half-metal ferromagnetism, Weyl and topological properties of $\mathrm{Sn}_{2} \mathrm{CO}_{3} \mathrm{~S}_{2}$, and semi conductivity of $\ln \mathrm{Sn}_{2} \mathrm{CO}_{3} \mathrm{~S}_{2}$ depend on only 3 bands, i.e. no 23, 24, and 25. Chemically, one can see these three bands as bonding, non-bonding, and antibonding states of interactions of $\mathrm{e}_{\mathrm{g}}$-orbitals $\left(\mathrm{Co}-3 \mathrm{~d}^{9}\right)$ within Co Kagomé layers. ${ }^{[9]}$ The position and topology of these bands is determined by Co-Co, but also by $\mathrm{Co}_{-} \mathrm{S}$ and $\mathrm{Co}-\mathrm{Sn}$-bands within $\mathrm{Sn}_{4} \mathrm{~S}_{2}$ polyhedra as studied by the electron localization function (ELF). ${ }^{[36,37]}$ According to first results on partial $M$ site substitution by $\mathrm{Ni}^{[38]}$ simultaneous substitution of A site atoms directs a way to tune band topology.

20 years ago, our DFT predictions initiated fascinating discoveries on $\mathrm{Sn}_{2} \mathrm{CO}_{3} \mathrm{~S}_{2}$. The present study focusses on DFT modeling of multinary shandites $A A^{\prime} M M_{2}^{\prime} S_{2}(M=\mathrm{Fe}, \mathrm{Co}, \mathrm{Ni}, A=$ In, $\mathrm{Sn}, \mathrm{Sb}$ ) that are isoelectronic to $\mathrm{Sn}_{2} \mathrm{Co}_{3} \mathrm{~S}_{2}$. First, their crystal structures are discussed, then electronic structures. The aim is to identify again interesting target systems for future studies.

\section{Results and Discussion}

\section{The $A A^{\prime} M M_{2}^{\prime} \mathrm{S}_{2}$ structure model}

In 1976 Michelet et al presented the structure of $\mathrm{Sn}_{2} \mathrm{Ni}_{3} \mathrm{~S}_{2}$ in a monoclinic cell of space group $C 2 / m(B 2 / m$ setting, $Z=2){ }^{[3]}$ Zabel transformed it to the trigonal shandite type cell $(R \overline{3} m){ }^{[4]}$ He related the deviation from cubic metrics to trigonal distortion and concluded that all shandites crystallize in isotypic structures. Metric relations of the trigonal cell in primitive rhombohedral $(r h, Z=1)$ and hexagonal (hex, $\mathrm{Z}=3$ ) setting and the monoclinic cell are illustrated in Figure 1. For $\mathrm{Sn}_{2} \mathrm{CO}_{3} \mathrm{~S}_{2}$ hexagonal $\left(a_{\text {hex }}=5.368(1) \AA, c_{\text {hex }}=13.177(1) \AA, V_{\text {hex }}=328.8 \AA^{3}\right.$, $\mathrm{Z}=3)$, trigonal $\left(a_{\mathrm{rh}}=5.376 \AA, \quad \alpha_{\mathrm{rh}}=59.91 \AA, \quad V_{\mathrm{rh}}=109,4 \AA^{3}\right.$, $\mathrm{Z}=1){ }^{[6-8]}$ and monoclinic $\left(a_{\mathrm{m}}=9.315 \AA, \quad b_{\mathrm{m}}=a_{\mathrm{rh}}, c_{\mathrm{m}}=a_{\text {hexi }}\right.$ $B=125.36^{\circ}$ ) unit cells are shown. By transformation of $B 2 / m$ setting to $C 2 / m$ the axis $b_{m}$ becomes $c_{m}$ and vice versa. Indeed, shandites with $A=\ln$ differ in trigonal distortion, with significant longer $c_{\text {hex }}$-axis $(13.6 \AA)$ and smaller angle $\alpha_{\mathrm{rh}}=57.9^{\circ}$ as shown in Figure 1. ${ }^{[6,10]}$ Table 1 presents the related atomic coordinates for the trigonal and monoclin cell for $\mathrm{Sn}_{2} \mathrm{CO}_{3} \mathrm{~S}_{2}$.

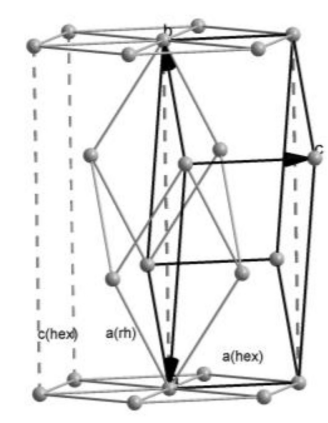

(a)

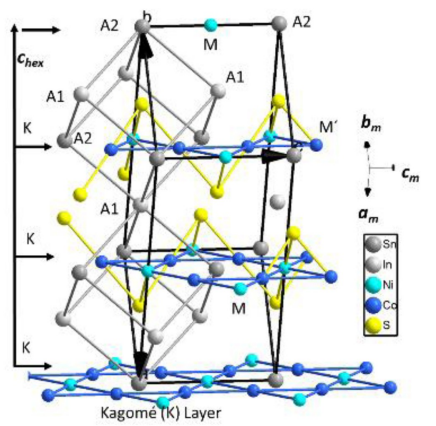

(b)
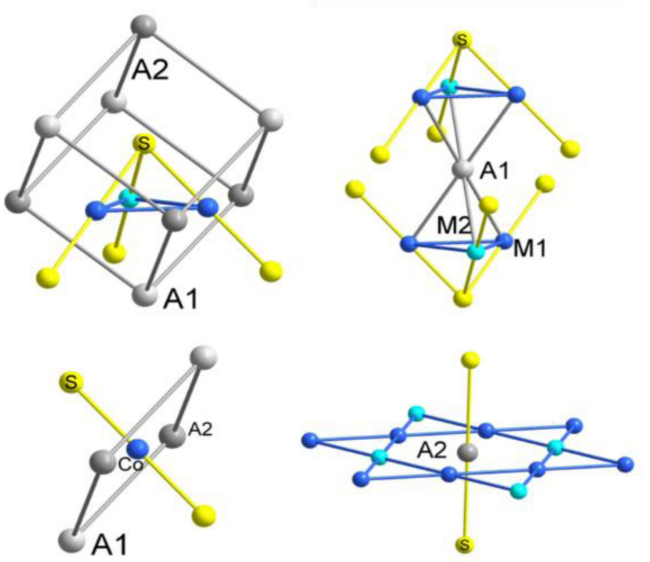

(c)

Figure 1. (a) metric relations of trigonal rhombohedral $(r h)$, hexagonal (hex), and monoclinic cell, (b) Model structure of $\ln \mathrm{SnNiCO}_{2} \mathrm{~S}_{2}$ (monoclinic cell), (c) atomic coordination spheres for $A 1, A 2, M$, and $\mathrm{S}$ sites. (main group metal $A=\mathrm{In}, \mathrm{Sn}, \mathrm{Sb}$; transition group metal $\mathrm{M}=\mathrm{Co}, \mathrm{Ni}$, Rh, Pd; chalcogen $X=\mathrm{S}$, Se Te).

Table 1. Atomic coordinates for $\mathrm{Sn}_{2} \mathrm{Co}_{3} \mathrm{~S}_{2}$, trigonal and monoclinic cells.

\begin{tabular}{|llll|}
\hline & Trigonal prim. $R \overline{3} m$ & Hexagonal $R \overline{3} m$ & Monoclinic $B 2 / m$ \\
\hline$A 1$ & $1 a(0,0,0)$ & $3 a(0,0,0)$ & $2 a(0,0,0)$ \\
$A 2$ & $1 b(1 / 2,1 / 2,1 / 2)$ & $1 b(0,0,1 / 2)$ & $2 c(1 / 2,1 / 2,0)$ \\
$M 1$ & $3 d(1 / 2,1 / 2,0)$, & $9 d(1 / 2,0,1 / 2)$ & $2 b(0,0,1 / 2)$ \\
$M 2$ & & & $4 f(1 / 4,1 / 2,1 / 4)$ \\
$X=\mathrm{S}$ & $2 c(\mathrm{z}, \mathrm{z}, \mathrm{z}=0.2828(1))$ & $6 c(0,0, z)$ & $4 i(1 / 2,-\mathrm{z}, 1 / 2+\mathrm{z}, 0)$ \\
\hline
\end{tabular}


Table 2. Compositions and calculated cell parameters from DFT-PBE-D3 structure optimizations.

\begin{tabular}{|c|c|c|c|c|c|c|c|}
\hline & SG & $\mathrm{a} / \AA ̊ \AA$ & $\mathrm{b} / \AA ̊$ & $c / \AA ̊$ & & $\gamma /{ }^{\circ}$ & $\mathrm{V} / \AA^{3}$ \\
\hline $\mathrm{Sn}_{2} \mathrm{Co}_{3} \mathrm{~S}_{2}$ & $B 2 / m$ & 9.291 & 5.349 & 5.300 & & 125.88 & 213.44 \\
\hline $\mathrm{Sn}_{2} \mathrm{CO}_{3} \mathrm{~S}_{2}$ & $R \overline{3} m$ & 5.300 & 5.348 & 13.159 & & 59.41 & 106.72 \\
\hline $\operatorname{lnSbCo} S_{2}$ & $B 2 / m$ & 9.499 & 5.421 & 5.231 & & 127.63 & 213.35 \\
\hline $\operatorname{lnSbCo} \mathrm{S}_{2}$ & $R \overline{3} m$ & 5.238 & 5.424 & 13.507 & & 57.75 & 107.00 \\
\hline $\mathrm{SblnCo}_{3} \mathrm{~S}_{2}$ & $B 2 / m$ & 9.072 & 5.281 & 5.406 & & 123.64 & 215.61 \\
\hline $\mathrm{SblnCo}_{3} \mathrm{~S}_{2}$ & $R \overline{3} m$ & 5.416 & 5.284 & 12.777 & & 61.66 & 108.18 \\
\hline $\operatorname{InSnCO}{ }_{2} \mathrm{NiS}_{2}$ & $B 2 / m$ & 9.588 & 5.470 & 5.271 & & 127.79 & 217.75 \\
\hline $\mathrm{SnInCo}_{2} \mathrm{NiS}_{2}$ & $B 2 / m$ & 9.311 & 5.412 & 5.340 & & 125.56 & 218.89 \\
\hline $\mathrm{In}_{2} \mathrm{CoNi}_{2} \mathrm{~S}_{2}$ & $B 2 / m$ & 9.646 & 5.452 & 5.330 & & 127.37 & 222.78 \\
\hline InSnFeNi ${ }_{2} S_{2}$ & $B 2 / m$ & 9.657 & 5.440 & 5.278 & & 127.60 & 219.72 \\
\hline $\mathrm{SnlnFeNi}{ }_{2} \mathrm{~S}_{2}$ & $B 2 / m$ & & 9.487 & 5.315 & 5.404 & 125.93 & 220.64 \\
\hline $\mathrm{SnSbFeCo} \mathrm{S}_{2}$ & $B 2 / m$ & & 9.269 & 5.337 & 5.262 & 125.90 & 210.90 \\
\hline $\mathrm{SbSnFeCO} \mathrm{S}_{2}$ & $B 2 / m$ & & 9.121 & 5.269 & 5.354 & 124.39 & 212.33 \\
\hline
\end{tabular}

In the trigonal cells Co atoms occupy $9 d(1 / 2,0,0)$ sites forming kagomé layers. Contrary Laves phases the atomic distances $\mathrm{d}_{\text {Co-Co }}=2.68 \AA=a_{\text {hex }} / 2$ therein are longer than in the respective element $\left(d_{\text {Co-Co }}=2.5 \AA\right)$, indicative for weak Co-Co interactions. Two main group metal sites $A=\mathrm{Sn}$ are found. $A 1$ site atoms on $3 a(0,0,0)$ interlink $\mathrm{Co}_{3}$ triangles between layers. The $A 2$ site on $3 b(0,0,1 / 2)$ is found in $M_{6}$ hexagons of the layers. Metal $\mathrm{Co}-\mathrm{Sn}$ bonds are suggested strong and determined by relations $\mathrm{d}_{\mathrm{Sn} 1-\mathrm{Co}}=a_{\mathrm{rh}} / 2$ and $\mathrm{d}_{\mathrm{Sn} 2-\mathrm{Co}}=a_{\text {hex }} / 2=d_{\mathrm{Co}-\mathrm{Co}}$. As shown for ordered structures of $\operatorname{InSnCo}{ }_{3} S_{2}$, A2 site atoms determine $A-M$ and $M-M$ distances in the layers, $A 1$ site atoms interlayerdistances. Co layers are spaced by $c_{\text {hex }} / 3=13.18 / 3 \AA=4.4 \AA$ with $A 1$ and $\mathrm{S}$ atoms on top and below $\mathrm{CO}_{3}$ triangles. In the HAP structure relation the Co atoms are found on faces of the $A=\mathrm{Sn}$ substructure centered by $\mathrm{S}$. In case of $\mathrm{Sn}_{2} \mathrm{CO}_{3} \mathrm{~S}_{2}$ the Co atoms occupy half of tetragonal bipyramid sites $\mathrm{Sn}_{4} \mathrm{~S}_{2}$. The $\operatorname{CoSn}_{4} \mathrm{~S}_{2}$ polyhedral are interlinked by faces within the layers and by Sn1 atoms between the layers. Therein short distances $d_{\text {co-s }}=2.18 \AA$ and linear $\mathrm{S}-\mathrm{M}-\mathrm{S}$ arrangements led to conclusion on covalent $\left[M_{3} S_{2}\right]$ networks.

Substitution of $A 1$ and $A 2$ site metals can be modeled in ordered structure of the trigonal cell as done for $\mathrm{InSnCo}_{3} \mathrm{~S}_{2}$. To model structures for compositions $A A^{\prime} M M_{2}{ }_{2} S_{2}$ with partial $A$ and $M$ site substitution, the monoclinic cell $(Z=2)$ is subsequently applied. $M$ sites split into $2 b$ and $4 f$. This allows to describe ordered $A A^{\prime} M M^{\prime}{ }_{2} \mathrm{~S}_{2}$ structures, e.g. for $\ln \mathrm{SnNiCO}_{2} \mathrm{~S}_{2}$.

\section{Crystal structure calculations}

Possible compositions and results for $A A^{\prime} M M^{\prime}{ }_{2} S_{2}$ compounds with $A=\mathrm{In}, \mathrm{Sn}, \mathrm{Sb}, M=\mathrm{Fe}, \mathrm{Co}, \mathrm{Ni}$ that are isoelectronic to $\mathrm{Sn}_{2} \mathrm{Co}_{3} \mathrm{~S}_{2}$ (47 valence electrons, VE) were summarized in Table 3. By simultaneous substitution of $A$ and $M$ sites number of electrons are balanced when electrons are added on one of the $A$ or $M$ sites and subtracted from the other. As an example, one $\mathrm{Co}$ atom is replaced by $\mathrm{Ni}$ (one electron more) in $\mathrm{Sn}_{2} \mathrm{Co}_{3} \mathrm{~S}_{2}$ and one $\mathrm{Sn}$ atom by In (one electron less) to obtain the composition InSnNiCo $\mathrm{S}_{2}$. DFT optimizations were performed with ordered model structures in the monoclinic cell of $B 2 / m$ setting.
Table 3. Compositions and calculated cell parameters form DFTPBE-D3 structure optimizations ( $B 2 / m$ cell).

\begin{tabular}{llllll|} 
& $a / \AA$ & $b / \AA$ & $c / \AA$ & $\gamma /{ }^{\circ}$ & $V / \AA^{3}$ \\
\hline $\mathrm{Sn}_{2} \mathrm{CO}_{3} \mathrm{~S}_{2}$ & 9.181 & 5.287 & 5.244 & 125.82 & 206.39 \\
$\mathrm{SnInCO}_{2} \mathrm{NiS}_{2}$ & 9.186 & 5.350 & 5.280 & 125.47 & 211.37 \\
$\mathrm{InSnCo}_{2} \mathrm{NiS}_{2}$ & 9.426 & 5.399 & 5.216 & 127.58 & 210.36 \\
$\mathrm{In}_{2} \mathrm{CoNi}_{2} \mathrm{~S}_{2}$ & 9.503 & 5.375 & 5.280 & 127.25 & 214.70 \\
$\mathrm{InSnFeNi}_{2} \mathrm{~S}_{2}$ & 9.525 & 5.379 & 5.216 & 127.47 & 212.11 \\
$\mathrm{SnInFeNi}_{2} \mathrm{~S}_{2}$ & 9.373 & 5.255 & 5.346 & 125.91 & 213.26 \\
$\mathrm{SnSbFeCO}_{2} \mathrm{~S}_{2}$ & 9.171 & 5.283 & 5.190 & 125.93 & 203.59 \\
$\mathrm{SbSnFeCo}_{2} \mathrm{~S}_{2}$ & 9.027 & 5.215 & 5.290 & 124.43 & 205.40 \\
$\mathrm{SblnCO}_{3} \mathrm{~S}_{2}$ & 8.983 & 5.225 & 5.333 & 123.84 & 207.88 \\
$\operatorname{InSbCO} \mathrm{S}_{2}$ & 9.368 & 5.347 & 5.168 & 127.57 & 205.18 \\
\hline
\end{tabular}

$\mathrm{Sn}_{2} \mathrm{Co}_{3} \mathrm{~S}_{2}, \operatorname{InSbCo} \mathrm{S}_{2}$, and $\mathrm{SblnCo}_{3} \mathrm{~S}_{2}$ were additionally calculated with trigonal cells. Here, and in all subsequent compositions $A$ site occupation is described by the order of the atoms $A 1 A 2 M M_{2} X_{2}$ with $A 1$ (between Co layers) and $A 2$ (in the layers).

The present calculations are based on models that imply $A 1-A 2$ and $M-M$ '-site ordering. In case of $\operatorname{InSnCo}{ }_{3} S_{2}$ the ordered structures turned out as good approximants for understanding crystal and electronic structures of the experimentally obtained samples. Therein, $\mathrm{Sn}$ prefers the $A 2$ sites in the kagomé layers and $\mathrm{In}$ the $A 1$ sites between them. Substitutions $M=\mathrm{Ni}, \mathrm{Co}, \mathrm{Fe}$ in shandites are experimentally known. Due to close atomic radii models with $M$ site ordering for $M=\mathrm{Fe}, \mathrm{Co}$, Ni should serve as suitable approximants for future experimental studies, too. This also accounts for predicted structures with $A=\mathrm{Sb}$, that are not known to date, but turn out as interesting candidates.

Table 2 summarizes results from full structural relaxations with the PBE functional. For $\mathrm{Sn}_{2} \mathrm{CO}_{3} \mathrm{~S}_{2}$ the present PBE calculations predict a volume of $107 \AA^{3}$, close experimental values at $-120^{\circ} \mathrm{C}$, and $103.2 \AA^{3}$ when dispersion interactions are accounted for by $\mathrm{PBE}+\mathrm{D} 3$ parametrization (Table 3 ). This trend is seen systematically for all studied compositions. Cell volumes from PBE +D3 calculations are approx. $2.5 \%$ smaller than from PBE calculations. One must conclude on contributions of dispersion interactions to bonding in shandites. A very simple isoelectronic substitution is found for $\ln \mathrm{SbCo}_{3} \mathrm{~S}_{2}$ and SblnCo $\mathrm{S}_{2}$ where In $(Z=49)$ has one electron less and $\mathrm{Sb}(Z=$ 
51) one electron more than $\mathrm{Sn}(Z=50)$. The calculated trigonal cells show only slightly larger volumes than $\mathrm{Sn}_{2} \mathrm{CO}_{3} \mathrm{~S}_{2}$. The hexagonal $c$ axis is much longer when $A 1=\ln$, but shorter for $A 1=\mathrm{Sb}$. The influence of the $A 2$ site atom is seen from $a_{\text {hex }}$ (= $\left.c_{\mathrm{m}}\right)$ that becomes longer for $A 2=\ln (5.42 \AA)$ than for $A 2=\mathrm{Sb}$ (5.30 ̊). Similar trends are known for $\ln \mathrm{SnCO}_{3} \mathrm{~S}_{2}{ }^{[18,19]}$

In the monoclinic cell setting the longer interlayer distances are reflected by larger values for $a_{\mathrm{m}}$ cell parameters, as seen for InSnCo $\mathrm{NiS}_{2}$ and $\mathrm{SnInCo}_{2} \mathrm{NiS}_{2}$. Again, In on interlayer $A 1$ sites causes longer interlayer distances than $A 1=\mathrm{Sn}$. As known from InSnCo $\mathrm{S}_{2}$ the exchange of $\mathrm{In}$ and $\mathrm{Sn}$ on $A 1$ and $A 2$ sites causes similar cell volumes. The increase in cell volume by $5 \AA^{3}$ compared to $\mathrm{Sn}_{2} \mathrm{Co}_{3} \mathrm{~S}_{2}$ is attributed to $\mathrm{Ni}$. On the other hand, In on $A 2$ sites causes similar bonding distances in kagomé layers as found for isoelectronic $\ln _{2} \mathrm{Ni}_{2} \operatorname{CoS}_{2}$. Here, the second $\mathrm{Sn}$ atom is replaced by $\mathrm{In}$ and an additional $\mathrm{Co}$ atom by $\mathrm{Ni}$ that causes again an increase in cell volume compared to $\mathrm{Sn}_{2} \mathrm{CO}_{3} \mathrm{~S}_{2}$.

Isoelectronic compounds are obtained when one Co atom is replaced by $\mathrm{Fe}$ instead of $\mathrm{Sn}$ by $\mathrm{In}$. Indeed, the cell volume calculated for $\mathrm{SnInFeNi}_{2} \mathrm{~S}_{2}$ is in the same range obtained for $\mathrm{SnlnCO} \mathrm{NiS}_{2}$. The insertion of $\mathrm{Sb}$ instead of $\mathrm{Sn}$ is predicted to cause a decrease in cell volume in $\mathrm{SnSbFeCO}_{2} \mathrm{~S}_{2}$. Interestingly, the $\mathrm{Sb}$ containing models are predicted with cell volumes close to $\mathrm{Sn}_{2} \mathrm{CO}_{3} \mathrm{~S}_{2}$. For so far, no shandites with $A=\mathrm{Sb}$ were prepared. There seems to be a limit in the stability of the shandite structure where pyrite related 1:1:1 compositions become more stable. To date in the phase diagram $\mathrm{Co}-\mathrm{Sb}-\mathrm{S}$ only CoSbS, but no " $\mathrm{Sb}_{2} \mathrm{Co}_{3} \mathrm{~S}_{2}$ " is known. However, the coexistence of both stoichiometries is known for $\mathrm{NiBiSe}$ and $\mathrm{Bi}_{2} \mathrm{Ni}_{3} \mathrm{Se}_{2}{ }^{[39]}$

The non-trivial relation of cell volumes and compositions is illustrated in Figure 2 from calculations on the equations-ofstate (EOS). Here, the results from $\mathrm{PBE}+\mathrm{D} 3$-calculations are shown. One can state that a huge range of differing cell volumes from $100 \AA^{3}$ to $107 \AA^{3}$ can be obtained for isoelectronic compositions. From the comparison of $\ln _{2} \mathrm{CoNi}_{2} \mathrm{~S}_{2}, \operatorname{InSbCO} \mathrm{S}_{2}$, and $\mathrm{SnSbFeCO} \mathrm{O}_{2} \mathrm{~S}$ one con conclude on effects of individual atoms on the cell volume. It is the composition and the specific site occupation that causes the cell volume. As mentioned before, electronic structure and magnetism of $\mathrm{Sn}_{2} \mathrm{Co}_{3} \mathrm{~S}_{2}$ is

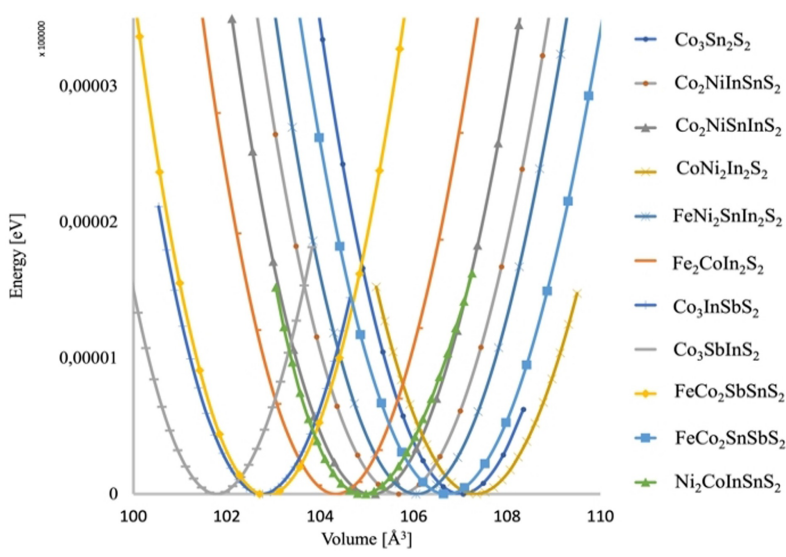

Figure 2. EoS-evaluation of the substitution series $M_{3} A_{2} S_{2}$ (non-spin polarization calculations with PBE-D3). known to be sensitive to the cell volume and the band structure of $\operatorname{InSnCO} \mathrm{S}_{2}$ is manipulated by $A$ site occupation. Substitution effects might thus be interesting to stabilize or to tune topological and magnetic states in $\mathrm{Sn}_{2} \mathrm{CO}_{3} \mathrm{~S}_{2}$.

\section{Electronic structure}

Fundamental concepts of the electronic structure of $\mathrm{Sn}_{2} \mathrm{CO}_{3} \mathrm{~S}_{2}$ are introduced in Figure 3 for further discussions. First, the orbital order in shandites is presented as obtained from analysis of the atomic orbital projected density of states (DOS, see ${ }^{[7,9]}$ and Figure 4a). Following the structure and composition, it is simply obtained from the atomic orbitals: four orbital states are received from two S-3s and $2 \mathrm{Sn}-5 \mathrm{~s}$ orbitals in $\mathrm{Sn}_{2} \mathrm{Co}_{3} \mathrm{~S}_{2}$. Next, six orbitals are introduced by sulfur $3 p$ orbitals of two $S$ atoms. Two occupied $S-3 s^{2}$, two $S n-5 s^{2}$, and six $S-3 p^{6}$ orbitals sum up to 10 bands and 20 electrons per FU. Co- $3 d^{9}$ states from 3 Coatoms sum up to $15 \mathrm{~d}$-orbitals and 27 electrons. Together with the S- and Sn-states 47 valence electrons and 25 bands are obtained. In a simple ionic view, the $\mathrm{Sn}-5 \mathrm{p}$ states remain empty in $\mathrm{Sn}_{2} \mathrm{Co}_{3} \mathrm{~S}_{2}$. However, they contribute to metallic bonding. ${ }^{[36,37]}$

For $\mathrm{Co}(0)-3 d^{9}$-configurations four $3 d$ orbitals are fully occupied for each Co atom resulting in 12 bands per formula unit $\mathrm{Sn}_{2} \mathrm{CO}_{3} \mathrm{~S}_{2}$. Adding 10 bands and 20 electrons from the " $\mathrm{Sn}_{2} \mathrm{~S}_{2}$ " partial structure we receive $10+12=22$ VB valence bands that are fully occupied by $20+24=44$ valence electrons. In the Co- $3 d^{9}$ state each Co-atom has one half occupied $\left(d_{z^{2}}\right)^{1}$ orbital. Applying a simple picture of linear combination of atomic orbitals (LCAO) per formula unit, the interaction of three Co-3d orbitals in $\mathrm{Sn}_{2} \mathrm{CO}_{3} \mathrm{~S}_{2}$, i.e., triangles of the layers, results in three states: bonging, nonbonding, and anti-bonding. In a simple chemical view, the prominent bands 23,24 , and 25 correspond to these states from $3 \mathrm{~d}$ interactions in the kagoménets as shown in Figure 3b. Accordingly, band no. 23 is fully

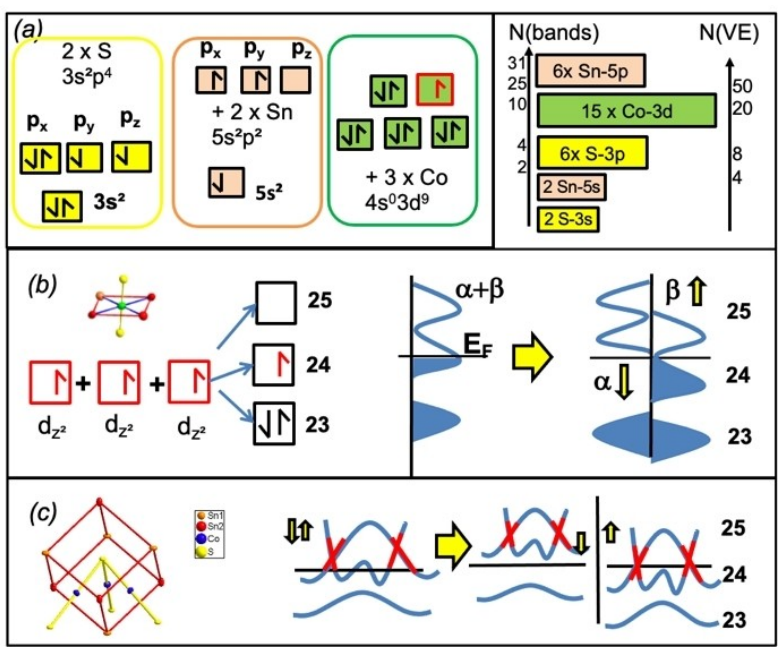

Figure 3. Scheme of the electronic structure of $\mathrm{Sn}_{2} \mathrm{CO}_{3} \mathrm{~S}_{2}$ with (a) LCAO scheme for the states of the atomic orbitals, (b) interaction of Co-3d orbitals in the valence band region, (c) bands in nonpolarized and spin polarized state. 


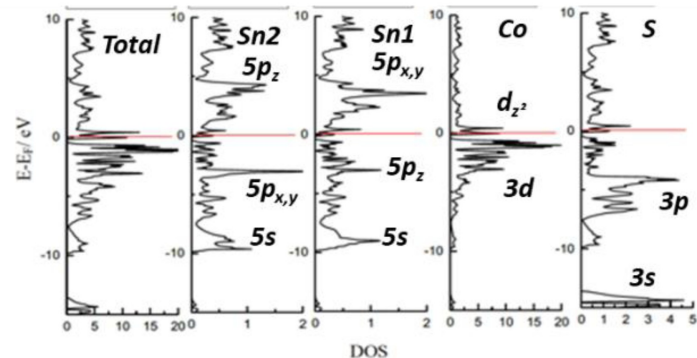

(a)

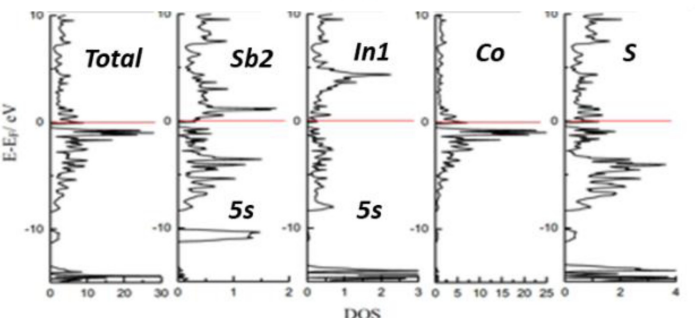

(b)

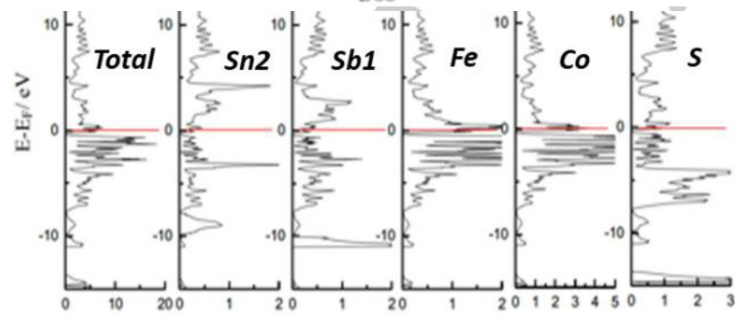

(c)

Dos

Figure 4. DOS plots for (a) $\mathrm{Sn}_{2} \mathrm{Co}_{3} \mathrm{~S}_{2}$, (b) $\ln \mathrm{SbCo}_{3} \mathrm{~S}_{2}$, (c) $\mathrm{SnSbFeCo}_{2} \mathrm{~S}_{2}$.

occupied, band no. 24 by only one electron per formula unit. This results in $44+2+1=47$ valence electrons. In the nonmagnetic regime this results in the metallic state with half occupied band no. 24. In the ferromagnetic state of $\mathrm{Sn}_{2} \mathrm{CO}_{3} \mathrm{~S}_{2}$ band 24 becomes empty for the minority state (down), but fully occupied for the majority spin direction (up). As found by the recent discoveries on topological properties, band 24 and 25 cross at two so called Weyl points that are found at $E_{F}$ for the majority spin direction, whereas $E_{F}$ is in the gap between band no. 23 and 24 for the minority spin direction. The respective scheme in Figure $3 \mathrm{c}$ signals the unique half metal ferromagnetic and Weyl semimetal state in $\mathrm{Sn}_{2} \mathrm{CO}_{3} \mathrm{~S}_{2}$.

Respective atomic site projected density of states is compared in Figure 4 for $\mathrm{Sn}_{2} \mathrm{Co}_{3} \mathrm{~S}_{2}, \mathrm{In} / \mathrm{Sb}$ - and Fe substitution. S$3 \mathrm{~s}$ bands are found at $-15 \mathrm{eV}, \mathrm{Sn}-5 \mathrm{~s}$ at -8 to $-10 \mathrm{eV}$, followed by $S-3 p$ from -3 to $-8 \mathrm{eV}$. $S n-5 p$ states are fond in a wide range from $+5 \mathrm{eV}$ to $-8 \mathrm{eV}$. Therein, $\mathrm{Sn} 1$ and $\mathrm{Sn} 2$ differ in degenerate $p_{x, y}$ and $p z$ contributions. The Co-3d states show main contributions to DOS states between +2 and $-4 \mathrm{eV}$ with main contributions below and minor above $E_{F}$. Just below the Fermi energy the prominent pseudo gap is found. States below represent the occupied 23 bands. Band no. 24 is represented by a DOS maximum at $E_{F}$, band no. 25 by a further maximum. Interestingly, orbitals of all atoms contribute to the respective DOS maxima. A simple interpretation was given by interactions in the tetragonal bipyramid coordination of the Co atoms, i.e., $\mathrm{CoS}_{2} \mathrm{Sn}_{4}$ in the structure of $\mathrm{Sn}_{2} \mathrm{Co}_{3} \mathrm{~S}_{2}$ (see HAP scheme).
From respective DOS plots for $\operatorname{lnSbCo}_{3} \mathrm{~S}_{2}$ and $\mathrm{SnSbFeCo}_{2} \mathrm{~S}_{2}$ (Figure 4) one can study effects of the substituting atoms. For $A=\ln$ the $5 \mathrm{~s}$ and $5 \mathrm{p}$ states are shift to higher, for $A=\mathrm{Sb}$ to lower energy. In case of $M=\mathrm{Fe}$ higher contributions to antibonding states at and above $\mathrm{E}_{\mathrm{F}}$ are found in comparison to Co. However, main characteristics of these bands including the Stoner instability at $E_{F}$ are maintained upon substitution. The compounds might be good candidates for interesting properties.

In Figure 5 specific effects on the electronic structures are analyzed with respect to the topology of their valence bands. The aim is to identify changes in the valence band region with respect to $\mathrm{Sn}_{2} \mathrm{CO}_{3} \mathrm{~S}_{2}$ for the design of possible future HFM or topological materials. The band structure of the parent compound $\mathrm{Sn}_{2} \mathrm{CO}_{3} \mathrm{~S}_{2}$ is presented in Figure $5 \mathrm{a}$ with the prominent topology including Weyl points. ${ }^{[7]}$ The dotted lines signal

(a)

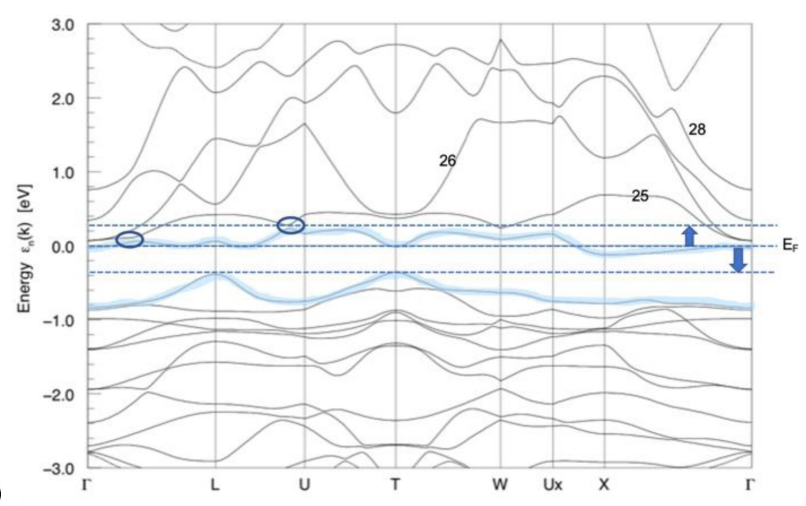

(b)

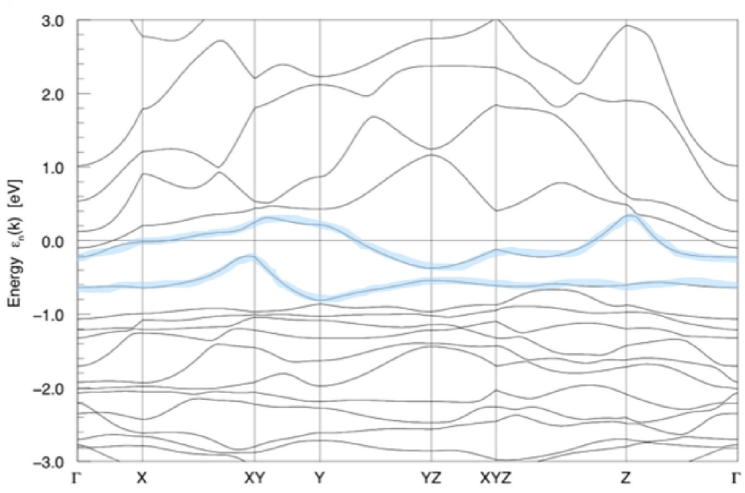

(c)

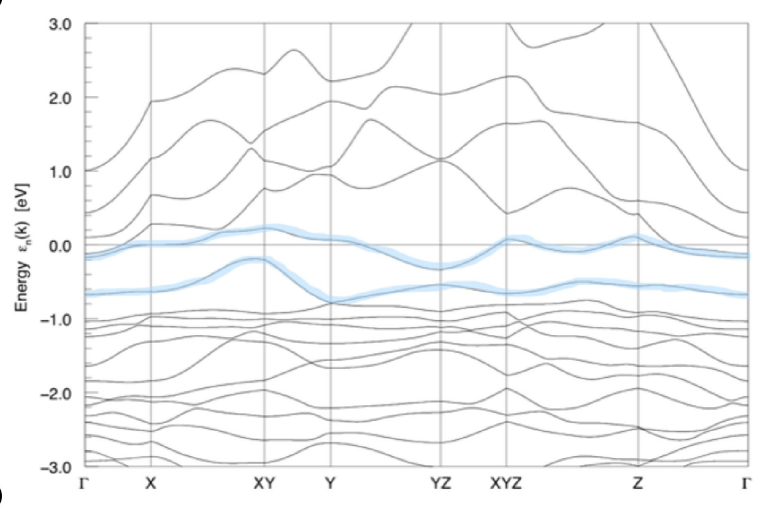

Figure 5. Electronic band structures of the substitutions series

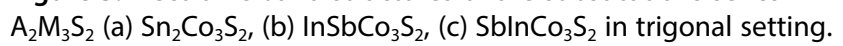


the range of the shift of EF for the minority and majority spin directions in the magnetic state. The prominent bands no. 23, 24 and 25 determine the HFM characteristics and the Weyl points. Bands no. 23 and 24 define the pseudo gap formed between them. In case of semiconducting $\ln \mathrm{SnCo}_{3} \mathrm{~S}_{2} \mathrm{E}_{\mathrm{F}}$ is found in this gap. In Figure 5 and 6 respective bands 23 and 24 were marked in light blue. In $\mathrm{Co}_{3} \mathrm{Sn}_{2} \mathrm{~S}_{2}$ the additional electron, that causes its magnetism, is found in band no. 24. Contacts to band no. 25 determine the prominent Weyl points along $\Gamma-L-U$. A simple comparison can be drawn to the modeled structure of $\ln \mathrm{SbCO}_{3} \mathrm{~S}_{2}$. For the first model, i.e., with $A 1=\ln$ between and $A 2=\mathrm{Sb}$ in the Co layers, the obtained band structure is very similar to $\mathrm{Sn}_{2} \mathrm{Co}_{3} \mathrm{~S}_{2}$. The pseudo gap is clearly stablished and bands 24 and 25 cross at several points. This situation should become interesting for the search for Weyl points and their modification in future studies. Similar to $\mathrm{SnInCO} \mathrm{S}_{2}$ a closing of the pseudo gap is seen for $\mathrm{SblnCo}_{3} \mathrm{~S}_{2}$ i.e. for $A 2=\mathrm{In}, A 1=\mathrm{Sb}$ that is attributed to multi-center bonds from analysis of the electron localization function ELF. ${ }^{[18,19,37,38]}$

Band structures calculated from monoclinic models are compared to $\mathrm{Sn}_{2} \mathrm{Co}_{3} \mathrm{~S}_{2}$ in monoclinic setting from Figure 6a. The band structures of $\operatorname{InSnCO} \mathrm{NiS}_{2}$ (c) and $\mathrm{SnInCO}_{2} \mathrm{NiS}_{2}$ (d) obey the rigid band behavior to first approximation as seen by comparison to $\mathrm{Sn}_{2} \mathrm{Co}_{3} \mathrm{~S}_{2}$. The principal scheme of the bands is maintained. However, the topology of the band's changes upon substitution of $\mathrm{Co}$ by $\mathrm{Ni}$ and $\mathrm{Sn}$ by $\mathrm{In}$ atoms and leads to a (a)

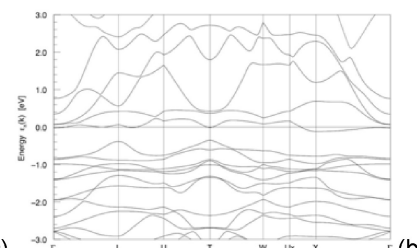

(c)

(e)

(g)

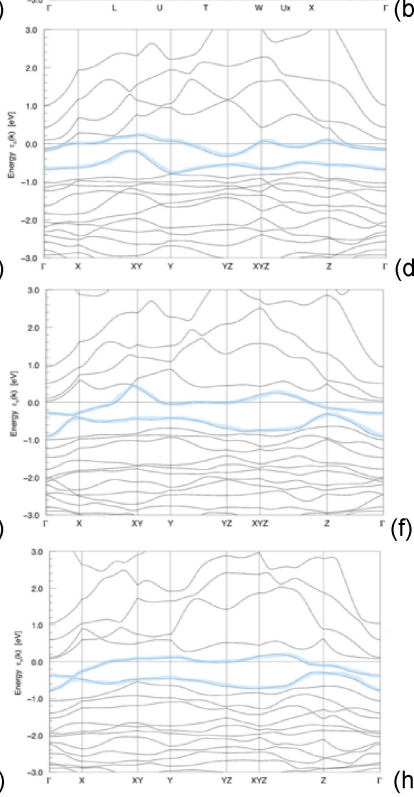

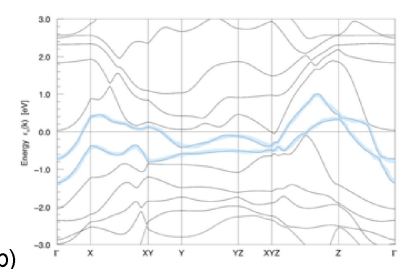

(d)

(f)

(h)

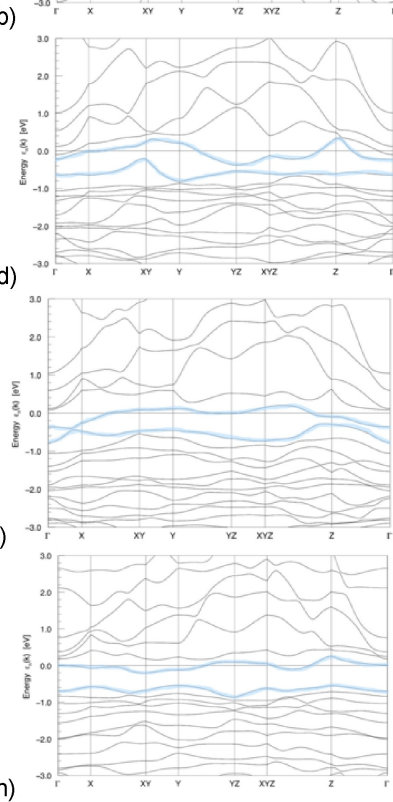

Figure 6. Calculated band structures for (a) $\mathrm{Sn}_{2} \mathrm{Co}_{3} \mathrm{~S}_{2}(C 2 / m$ cell), (b) $\ln _{2} \mathrm{CoNi}_{2} \mathrm{~S}_{2}$, (c) InSnCo $\mathrm{NiS}_{2}$, (d) $\mathrm{SnInCO} \mathrm{NiS}_{2}$, (e) $\mathrm{SnInFeNi} \mathrm{S}_{2}$, (f) $\operatorname{lnSnFeNi} \mathrm{S}_{2}$, (g) $\mathrm{SbSnFeCo}_{2} \mathrm{~S}_{2}$, (h) $\mathrm{SnSbFeCo}_{2} \mathrm{~S}_{2}$. diminished pseudo gap and increased band dispersion. Contacts of band 24 and 25 that may cause the Weyl points in $\mathrm{Sn}_{2} \mathrm{CO}_{3} \mathrm{~S}_{2}$ are modified. For $\ln _{2} \mathrm{Ni}_{3} \mathrm{~S}_{2}$. $\ln _{2} \mathrm{CoNi}_{2} \mathrm{~S}_{2}$ does not show a recognizable electronic gap between the two bands. Additionally, both bands cross the fermi level. Therefore, this compound indicates pure metallic properties. With increasing In content half metal states might not be obtained upon spin polarization.

Less expressed differences upon $A 1, A 2$ site occupation are seen for $\mathrm{InSnFeNi} \mathrm{S}_{2}$ and $\mathrm{SnInFeNi} \mathrm{S}_{2}$ pictured in Figure $6 \mathrm{~g}, \mathrm{~h}$.

The band structures of $\mathrm{SbSnFeCO}_{2} \mathrm{~S}_{2}$ and $\mathrm{SnSbFeCO} \mathrm{S}_{2}$ (Figure 6(i) and (j)) do not show large differences in the band structure upon $\mathrm{Sn}-\mathrm{Sb}$ ordering. Here, the pseudo gap is clearly expressed, and the compounds might be good candidates for HFM materials.

As seen best for $\operatorname{InSbCo}{ }_{3} S_{2}$, the mentioned models are good candidate with respect to possible HFM behavior and variation of band topology. The substitutions indicate ways to modify the topology of the band structures and the magnetism of $\mathrm{Sn}_{2} \mathrm{CO}_{3} \mathrm{Sn}_{2}$ and to find novel interesting properties. However, the mentioned properties must be probed by spin polarized calculations with spin-orbit coupling (SOC) in subsequent studies and by experiment.

\section{Conclusion}

Starting from shandite type anisotropic $\mathrm{S}=1 / 2$ half metal ferromagnet and Weyl semimetal $\mathrm{Sn}_{2} \mathrm{Co}_{3} \mathrm{~S}_{2}=\mathrm{CO}_{3} \mathrm{Sn}_{2} \mathrm{~S}_{2}$ isoelectronic model compounds were investigated by DFT calculations. From electron counting of 47 valence electrons chemical compositions $A A^{\prime} M M_{2}^{\prime} S_{2}$ were chosen. Balance of the number of electrons was ensured by choice of $A=\ln , \mathrm{Sn}, \mathrm{Sb}$ and $M=\mathrm{Fe}$, Co, Ni. Model structures were obtained by partial substitution of the metal $A$ and $M$ sites in low symmetry cells. Thereby, hitherto unknown compositions including $A=\mathrm{Sb}$ and $M=\mathrm{Fe}$ were considered. According to full structure optimizations within DFT calculations the substitutions allow to alter the cell volume within $10 \%$ range compared to $\mathrm{Co}_{3} \mathrm{Sn}_{2} \mathrm{~S}_{2}=\mathrm{Sn}_{2} \mathrm{CO}_{3} \mathrm{~S}_{2}$ Structure distortions in terms of interlayer and intralayer atomic distances are shown to depend on compositions atomic site preference. For all compositions specific effects on the electronic structures are found, especially on the three bands that determine half metal and topological features of $\mathrm{Sn}_{2} \mathrm{CO}_{3} \mathrm{~S}_{2}$. According to electronic structures several compositions are identified as targets for future experimental and theoretical investigations on magnetic and topological properties. The modeled structures are considered as helpful approximants to study experimental data and to discover novel fascinating multinary shandites as seen for $\mathrm{Sn}_{2} \mathrm{CO}_{3} \mathrm{~S}_{2}$ during the last 20 years.

\section{Experimental Section}

Calculations of the full structural optimizations and the Equations of State (EoS) were performed by using an LCGTF (linear combination of Gaussian type functions) scheme, which is implemented in the Crystal17 code. ${ }^{[40,41]}$ In the structural optimiza- 
tion as in the calculations of the EOS, the energy considering convergence criteria was set to $10^{-8} \mathrm{H}$. All DFT studies for structural optimizations started with the parameters $a=9.331 \AA, b=5.403 \AA$, $\mathrm{c}=5.458 \AA$ and $\gamma=124.55^{\circ}$. The EOS calculations correspond to ones of Birch-Murnaghan. For $\mathrm{Co}, \mathrm{Sn}, \mathrm{S}, \mathrm{Fe}, \mathrm{In}, \mathrm{Ni}$, Sb full electron basis sets were used. ${ }^{[42,43]}$

All calculations of this work were performed with the GGA functional according to Perdew-Burke- Ernzerhoff (PBE) and its extension by Grimme (PBE-D3). ${ }^{[44,45]}$ Convergence criteria were partly varied and amounted to $10^{-6}$ or $10^{-8}$. These are indicated in the input of a calculation, with the keyword TOLDEE. As SHRINK factor (4 8), (6 12) or (12 24) were used. This gives the number of kpoints considered. In the spin-polarized calculations, a SPINLOCK was also used starting with (17) up to (160) was used. For both the geometry optimizations and the EOS calculations, a SPINLOCK was used for the case that in case they did not converge, a MAXCYCLE of 100 was inserted as needed. Additionally, or alone in the same case, TOLDEE of 6 or 8 was inserted. The band structures and the DOS structures were calculated with FPLO. ${ }^{[4]}$

\section{Acknowledgements}

Open Access funding enabled and organized by Projekt DEAL.

\section{Conflict of Interest}

The authors declare no conflict of interest.

Keywords: $\mathrm{Ab}$ initio calculations $\cdot \mathrm{CO}_{3} \mathrm{Sn}_{2} \mathrm{~S}_{2} \cdot$ shandite electronic structure $\cdot$ Half antiperovskite $\cdot$ Substituent effects

[1] P. Ramdohr, Sitzungsberichte der Deustchen Akademie der Wissenschaften zu Berlin (Mathematisch-naturwissenschaftliche Klasse, Jahrgang 1949). 1950, 6, 425-439.

[2] M. A. Peacock, Joh. McAndrew, Am. Mineralog. 1950, 35, 425439.

[3] J. E. Hiller, N. Jahrb. Mineral. 1951, 12, 265-277.

[4] A. Michelet, G. Collin, O. Gorochov, J. Less-Common Met. 1984, $97,73$.

[5] S. Natarajan, G. V. Subba Rap, R. Baskaran, T. S. Radhakarishnan, J. Less-Common Met. 1988, 138.2, 215-224.

[6] M. Zabel, S. Wandinger, K.-J. Range, Z. Naturforsch. 1979, 34b, 238.

[7] R. Weihrich, PhD Thesis, University of Regensburg, 2001.

[8] R. Weihrich, I. Anusca, Z. Anorg. Allg. Chem. 2006, 632, 15311537.

[9] R. Weihrich, R. Pöttgen, F. Pielnhofer, Angew. Chem. Int. Ed. 2018, 57, 15642-15644; Angew. Chem. 2018, 130, 1586815870.

[10] R. Weihrich, I. Anusca, M. Zabel, Z. Anorg. Allg. Chem. 2005, $631,1463-1470$.

[11] R. Weihrich, S. F. Matar, V. Eyert, F. Rau, M. Zabel, M. Andratschke, I. Anusca, Th. Bernert, Prog. Solid State Chem. 2007, 35, 309-20.

[12] R. Weihrich, K. Köhler, F. Pielnhofer, Sebastian Haumann, From 3D intermetallic antiperovskites to 2D Half antiperovskites. Encyclopedia of Inorganic and Bioinorganic Chemistry, 2017, DOI: 10.1002/9781119951438.eibc2498.

[13] T. Kubodera, H. Okabe, Y. Kamihara, M. Matoba, Phys. B 2006, 378,1142
[14] W. Schnelle, A. Leithe-Jasper, H. Rosner, F. M. Schappacher, R. Pöttgen, F. Pielnhofer, R. Weihrich, Phys. Rev. B 2013, 88, 144404-12.

[15] M. Holder, Yu. S. Dedkov, A. Kade, H. Rosner, W. Schnelle, A. Leithe-Jasper, R. Weihrich, S. L. Molodtsov, Phys. Rev. 2009, $B 79,205116-9$.

[16] X. Lin, S. Bud'ko, P. C. Canfield, Phil. Mag. 2012, 92, 2436.

[17] A. Umetani, E. Nagoshi, T. Kubodera, M. Matoba, Phys. 2008, B 403, 1356 .

[18] J. Rothballer, F. Bachhuber, S. M. Rommel, T. Söhnel, R. Weihrich, RSC Adv. 2014, 4, 42183-42189.

[19] F. Pielnhofer, J. Rothballer, P. Peter, W. Yan, F. Bachhuber, R. Weihrich, Z. Anorg. Allg. Chem. 2014, 640, 286-294J.

[20] J. Corps, P. Vaquiero, A. Aziz, R. Grau-Crespo, W. Kockelmann, J. C. Jumas, A. V. Powell, Chem. Mater. 2015, 27, 3946-3956.

[21] M. A. Kassem, Y. Tabata, T. Waki, H. Nakamura, J. Crystal Growth 2015, 426, 208.

[22] P. Gütlich, K.-J. Range, C. Felser, C. Schultz-Munzenberg, W. Tremel, D. Walcher, M. Waldeck, Angew. Chem. Int. Ed. 1999, 38, 2381.

[23] F. Pielnhofer, A. S. Tragl, J. Rothballer, Z. Naturforsch. 2014, 69, 55-61.

[24] M. A. Kassem, Y. Tabata, T. Waki, H. Nakamura, J. Solid State Chem. 2016, 233, 8.

[25] M. A. Kassem, Y. Tabata, T. Waki, H. Nakamura, Phys. Rev. 2017, B 96, 014429

[26] D. F. Liu, A. J. Liang, E. K. Liu, Q. N. Xu, Y. W. Li, C. Chen, D. Pei, W. J. Shi, S. K. Mo, P. Dudin, T. Kim, C. Cacho, G. Li, Y. Sun, L. X. Yang, Z. K. Liu, S. S. P. Parkin, C. Felser, Y. L. Chen, Science 2019, $365,1282-1285$

[27] E. Liu, Y. Sun, N. Kumar, L. Muechler, A. Sun, L. Jiao, S.-Y. Yang, D. Liu, A. Liang, Q. Xu, J. Kroder, V. Süß, H. Borrmann, Ch. Shekhar, Z. Wang, C. Xi, W. Wang, W. Schnelle, S. Wirth, Y. Chen, S. T. B. Goennenwein, C. Felser, Nat. Phys. 2018, 14, 1125.

[28] H. C. Wu, P. J. Sun, D. J. Hsieh, H. J. Chen, K. D. Chandrasekhar, L. Z. Deng, C. W. Chu, H. D. Yang, Mater. Today Phys. 2020, 12, 100189.

[29] A. Ali, S. Shama, Y. Singh, J. Appl. Phys. 2019, 126, 155107.

[30] M. A. Kassem, A. Tabata, T. Waki, H. Nakamura, J. Phys. Condens. Matter 2021, 33, 015801.

[31] K. Geishendorf, R. Schlitz, P. Vir, C. Shekhar, C. Felser, K. Nielsch, S. T. B. Goennenwein, A. Thomas, Appl. Phys. Lett. 2019, 114, 092403.

[32] C. Liu, C. Yi, X. Y. Wang, J. L. Shen, T. Xie, L. Yang, T. Fennel, U. Stuhr, S. L. Li, H. M. Weng, Y. G. Shi, E. Liu, H. Q. Luo, Science China Phys. 2021, 64, 257511., .

[33] Y. Araki, J. Watanabe, K. Nomura, J. Phys. Soc. Japan 2021, 90, 094702.

[34] S. Howlader, R. Ramachandran, Y. Singh, G. Sheet, J. Phys. Condens. Matter 2020, 33.5, 075801.

[35] V. Meschke, P. Gorai, V. Stevanović, E. S. Toberer, Chem. Mater. 2021, 33, 4373-4381. .

[36] R. Weihrich, W. Yan, J. Rothballer, Ph. Peter, S. M. Rommel, S. Haumann, F. Winter, Ch. Schwickert, R. Pöttgen, Dalton Trans. 2015, 44, 15855-15864.

[37] I. Anusca, A. Schmid, P. Peter, J. Rothballer, Z. Anorg. Chem. 2009, 635, 2410-2428.

[38] G. S. Thakur, P. G. Vir, Praveen, S. N. Guin, Ch. Shekhar, R. Weihrich, Y. Sun, N. Kumar, F. Felser, Chem. Mater. 2020, 32, 1612-1617.

[39] S. M. Rommel, A. Krach, P. Peter, R. Weihrich, Chem. Eur. J. 2016, 22, 6333-6339.

[40] R. Dovesi, A. Erba, R. Orlando, C. M. Zicovich-Wilson, B. Civalleri, L. Maschio, M. Rerat, S. Casassa, J. Baima, S. Salustro, B. Kirtman, WIREs Comput. Mol. Sci. 2018, 8, e1360. 
[41] R. Dovesi, V. R. Saunders, C. Roetti, R. Orlando, C. M. ZicovichWilson, F. Pascale, B. Civalleri, K. Doll, N. M. Harrison, I. J. Bush, P. D'Arco, M. Llunell, M. Causà, Y. Noël, L. Maschio, A. Erba, M. Rerat, S. Casassa, CRYSTAL17 User's Manual (University of Torino, Torino, 2017).

[42] „CRYSTAL - Theoretical Chemistry Group, "CRYSTAL- A computational tool for solid state chemistry and physics, "Basis sets," 2018. [Online]. Available: http://www.crystal.unito.it/ Basis_Sets/cobalt.html.

[43] M. Towler, "CRYSTAL Ressource Page," 2018. [Online]. Available: http://www.tcm.phy.cam.ac.uk/ mdt26/basis_sets/.
[44] S. Grimme, A. Hansen, J. G. Brandenburg, C. Bannwarth, Chem. Rev. 2016, 116, 5105-5154.

[45] S. Grimme, S. Ehrlich, L. Goerigk, J. Comb. Chem. 2011, 32, 1456.

[46] I. Opahle, K. Koepernik, H. Eschrig, Phys. Rev. B 1999, 60, 14035.

Manuscript received: June 2, 2021

Revised manuscript received: December 17, 2021

Accepted manuscript online: December 24, 2021 